\title{
Transparency - more than a buzzword?
}

The "transparency trend" is hot for the summer of 2011. At least that is what they said in the fashion capitals of Milan, Paris, and London. In the new summer collections, sheer seethrough dresses reveal the beauties of the human body and leave little to the imagination. Architects too are attracted by the intriguing properties of transparent materials to create a new perception of space and boundaries, which challenges some traditional understandings of private living and daily work life. Whereas in the past, it was a Puritan statement to live without curtains at the windows, to show you had nothing to hide, today, the transparent way of life is often used to enable the owner to display their wealth and luxury. Institutions have increasingly followed this transparency trend in fashion and architecture by using glass for their buildings.

Transparency is not only a fashion trend, but also a political challenge. Fashion and politics meet in the huge glass buildings of the European Union in Brussels and Strasbourg, which reflect the Union's strategy to improve its democratic legitimacy; one of the main aims of the Lisbon Treaty (2009). In terms of adaption to this see-through trend, institutions are not only voluntarily moving towards greater transparency, they are being ambushed by those who believe that information is a public good, which should not be guarded by a few. By revealing "suppressed and censored injustices" (WikiLeaks, n.d.), WikiLeaks practices what some call "guerrilla transparency" (The Economist, 2010). When people think of transparency, the recent commotion caused by WikiLeaks' publication of thousands of documents on nationally and internationally sensitive issues is at the forefront of their minds. This event has triggered a worldwide debate on the balance between state security and citizens' right to know.

It is not just politicians who have to think about their transparency when developing their relations with citizens. Since the dramatic consequences of the financial crisis, people are demanding to be able to follow the flows of their money and are calling for the accountability of those working in the banking sector, for example, through scrutiny of their bonuses. According to Transparency International (2011), for instance, the banking system should be more transparent as it "fights fraud and corruption, Improves market efficiency [and] Investor protection" (p.4). This is particularly emphasized when it comes to aid effectiveness, and the role of world banks in the international economic development sector. 
However, people's demands for increased transparency transcend the world of politics. In their daily lives, citizens are no longer satisfied with blind consumption, but increasingly look for products which are labeled with the origin and production standards, in order to feel that they are becoming informed consumers. This has triggered the emergence of fair trade, organic, and health labeling to convince consumers of the 'good behavior' of suppliers and producers. When two people share the same amount of information with regard to a certain topic, they are more likely to trust each other - simply because both sense that they could not be easily betrayed by the other as they hold the same power resources (i.e. information) (Hinnant, Rae Moon \& Welch, 2004). It is in this respect that transparency can improve interpersonal relationships, including between a consumer and a producer.

However, there is another side of the coin. The increase in citizens' demand for knowledge about consumption or governmental actions exists along with an awareness and concern of the amount of surveillance of citizens taking place in modern society. After the attacks of 9/11, many people are concerned about the increasing demand for securitization. This can lead to a radicalization of surveillance, as conceptualized by Bentham's project of the Panopticon or by Poster's (1995) development of the notion of the super-panopticon. In this sense, imposed personal transparency is often understood as the destruction of privacy, anonymity and freedom, making transparency the "mass murder of social life" (Time in the Shadows, n.d.).

The concept of transparency can be applied to nearly every domain of human activity. In the political sphere, voters strive to acquire as much information as possible about a candidate's proposed policies and, increasingly, about the candidate himself. In the economic sphere, job recruiters consult social networking websites in order to get a more accurate impression of possible future employees. The trend concerning the concept of transparency has also affected the pharmaceutical industry and the scientific community, both of which often seen to suffer from serious, non-transparent drawbacks. Pharmaceutical companies are increasingly confronted with the demand to disclose information surrounding the procedures by which new medications are released to the market. Additionally, critical voices have been raised that the population is not sufficiently informed about adverse side-effects of these medications. This, too, is a domain in which the patients call for an expansion of transparency. Finally, even in the domain of development aid, the issue of transparency has taken root. Over the last decades, the focus has shifted from purely emphasising the importance of the transparency of providers of development aid to demanding that the recipients of this aid should also make their work more transparent. 
In each of these diverse domains transparency is thought to provide the public with information in order to make reasoned judgements: be it information about who to vote for, who to employ, which medications to take, or which Non Governmental Organization to support. If people are sufficiently informed, the argument goes, they are able to hold political officials accountable, find more competent staff, and even punish mismanagement and corruption. As Bessire (2005) puts it, "transparency is strongly related to information - and information is power" (p. 429).

This line of reasoning ignores the fact that the availability of information is not the only aspect of accountability. If the public does not know what is happening behind closed doors, it naturally has no incentive - and indeed no chance - to hold somebody accountable necessary. As well as having access to relevant information, people must have measures at their disposal to punish responsible actors. Or, as Lindsay Stirton and Martin Lodge (2001) put it in reference to transparency in the political domain: "simply knowing what public service providers have decided and why they think they make a good decision is not a particularly valuable form of transparency, especially if citizens cannot exercise some input into public-decision making" (p.475) - and, in the last resort, also dispose over measures of punishment.

There is also the problem that transparency could easily lead to an overload of information. Onora O'Neill (2002) argues that the thoughtless provision of information to the public opens up the possibility for some actors to spread misinformation. The pharmaceutical sector and the scientific community, for example, are marked by a thin line between disclosure of information and release of medications, and (health) risks for the population. This means that information provided must be intelligible for recipients for transparency have a beneficial effect. As indicated above, since the conception of transparency has moved away from the purely physical, numerous scholars have investigated the notion from different angles. A theoretical discourse has been developed in numerous fields, including philosophy, politics and, lately, economics. The following section will give an outline of a selection of these concepts, to provide an overview of the existing debate. It merely covers a selection of the huge range of relevant discussions, but is intended to provide a clear introduction to the concepts which form the foundation of the specific cases analyzed in the volume.

First, the discussion focuses on the political dimension of transparency. This aspect is elaborately investigated by Christopher Hood and David Heald (2006) in their book Transparency: The Key to Better Governance. Hood distinguishes between pre-twentieth century and modern ideas of transparency and claims that "Transparency is a term that has attained quasi religious significance in debate over governance and institutional 
design"(p.3). He differentiates between transparency in different levels of government. Hood establishes several "doctrines of openness" for transparency within International Governance (p.11). He particularly emphasizes the importance of transparency of interstate agreements and the obligation for nation states to disclose information towards international bodies. The openness of inter-state agreements has grown in significance since World War I and the consequences of the many secret arrangements between states. According to Hood, this secretiveness and its devastating consequences have introduced Transparency into the field of international negotiations.

On the other hand, the necessity for national governments to reveal information was initiated "in the interest of making international policy regimes effective" (p.12). This idea is supported by Joseph Stiglitz (1999) who argues that secrecy leads to increased domination over particular sections. This again results in the growth of power for certain actors (p.2). Thus, the disclosure of information helps to balance the power between national and international bodies. On the National and Sub-national level Transparency the focus lies on the relationship between the government and its people (Hood, 2006, p.12). On this level the need to make government information accessible for all citizens is emphasized as this gives people the opportunity to monitor the work of their government which "makes abuses of governmental powers less likely [and] also enhances the likelihood that basic social needs will be met" (Stiglitz, 1999, p.1).

David Heald (2006) establishes abstract conceptions which describe the direction transparency might take. "Vertical transparency" requires a hierarchical relationship between the actors involved and consists of "upwards" and "downwards" transparency, depending on who in the relationship holds the power to monitor the other. Transparency upwards exists where "the superior/principle can observe the conduct, behavior, and/or results of the subordinate/agent" (p.27). For example, this might occur when governments collect and store private data about their citizens. Nowadays transparency upwards is a highly debated topic, as more and more information about citizens is accumulated by official institutions. Transparency downwards occurs when a subordinate is able to observe their superior (ibid.). This would mean the ability of citizens to monitor the actions of their government, which could lead to a higher degree of accountability. "Horizontal transparency", on the other hand, refers to the relationship between contemporaries. "Transparency inwards" occurs when somebody outside a body or an organization can access data from within this organization. "Transparency outwards" means that an agent from inside an organization is able to monitor surrounding organizations, which is "fundamental to an organization's capacity to understand its habitat and to monitor the behavior of its peers and/or competitors" (p.28). This kind of transparency is, for instance, 
important for the relationship between opposing companies. For Heald (2006), these directions of transparency cover the majority of the political sphere and related fields.

Moreover, Heald defines four variations of transparency, concentrating both on what is transparent and on the point at which information becomes available. First, he defines event and process transparency. Events are conceived as situations which can be monitored from outside and, for the most part, can be measured (p.30). Thus, if inputs and results are observable, while the working process remains hidden, Heald's conception of "event transparency" applies. On the other hand, when the procedures leading to the respective results are visible to "all those who are interested in a decision to understand what is being decided and why" (Neyland, 2007, p.501), Heald (2006) speaks of "process transparency". The other two variations are concerned with when information becomes accessible. First, "transparency in retrospect [...] allows an organization to conduct its business and then, at periodic intervals, to release information relevant to its performance" (p.32). This means that the working process can only be evaluated after has been completed. In contrast, "transparency in real time" allows continuous monitoring of internal procedures by disclosing information at every stage during the process (p.33). Thereby it becomes possible to intervene from outside if necessary.

G. Randolph Mayes (2010) explores additional aspects of the directions of transparency and thereby complements the concepts developed by Hood and Heald. Heald's (2006) four dimensions mainly concentrate on an institutional level, however "we should notice that transparency has nowadays invaded even the most insignificant aspects of our life" (Bessire, 2005, p. 425). Thus, Mayes' concept, which is applicable to other fields of society, is important to include as a background to our analysis. In his article Privacy in a Transparent Society, he classifies transparency into omni- and unidirectional transparency. Unidirectional transparency occurs when information of one actor is accessible to another actor, while the latter is able to secure his or her own information from intrusion from outside (Mayes, 2010, p.18). The transparent individual or institution is not only incapable of assessing another actor's data, but is often even not aware of the fact that his or her own information is accessed. In contrast, omni-directional transparency occurs in a "society in which the activities of private citizens, multinational corporations, and government are all becoming easier for anyone to observe" (ibid.). In this case, the data of every actor involved is openly available; hence no situation of asymmetry occurs. This is supported by Bessire (2005) who argues that "improving transparency is assumed to reduce this asymmetry and therefore to prevent agents from adopting opportunistic behaviours" (p.426). Mayes (2010) claims that the society in which we live is increasingly predominated by omnidirectional transparency, as general information is available about every individual as well as every institution (p.18). 
Subsequently, there are both positive and negative expectations attached to the concept of transparency. What is needed, therefore, is further refinement of what is actually meant when talking about transparency. Such refinements are inevitably context-based. This is exactly what this volume aims to do: it takes the concept of transparency and attempts to show its implications in the political domain, in the job seeking process, in social media, development aid, and the pharmaceutical industry. The various conceptualizations of transparency discussed above provide a starting point for the different articles of this volume, through which the changing character of transparency in a globalized world is highlighted. Transparency Trends: changing expectations of transparency in a globalizing world is a volume that seeks to contextualize transparency in a world that is increasingly dominated by networks and flows of information. How our authors position themselves in the debate on transparency and its expectation will be outlined in the following. Interestingly, all contributions take an instrumental stance on transparency. We shall further discuss this observation in the Conclusion to this volume.

The volume starts with a micro-level perspective on transparency as Paul Beckmann, Alexander Hoppe, Katharina Jautz, Lara Schartau and Julia Schmälter claim that the emergence of Social Networking Sites (SNS) such as Facebook increases the transparency of the individual. In order to test this hypothesis and its implications for every-day life, they analyzed the case of the job recruitment procedure. As users of SNS disclose more and more information online, personal transparency increases at the expense of the private sphere. This shifting pattern is generally conceptualized as omnidirectional transparency among users of SNS. For the case of the job-recruitment procedure, however, job seekers' transparency can be described as 'unidirectional transparency upwards' as recruiters have a superior position towards the applicants. Considering this hierarchical personal transparency within the framework of screening and signaling, Beckmann et al. argue that SNS provide job recruiters with a new possibility for increased screening of applicants, using the job seekers' transparency for determining the person-organization fit. The case study builds upon a mixed-method approach including a quantitative survey with both, German and Dutch recruiters and job seekers as well as qualitative interviews with recruiters. The results of the study suggest that growing personal transparency on SNS clearly has the potential to change the relationship between recruiters and job seekers.

Since the fifties, many popular newspapers, magazines and television programs have paid attention to the private lives of public figures, and have increased their transparency at the cost of their privacy. (Pels, 2003, p. 42) The new media, such as Twitter and Facebook, created even more possibilities to blur the border between the public and private sphere, by enabling its user to keep their audience up-to-date at any moment of the day. In this article, 
Anne Theunissen discusses the dominant media trends, and relate these to the public and private lives of politicians. Furthermore, she investigates how Dutch politicians use the new medium of Twitter, in order to determine whether they confirm the media trends. This reveals to what extent the norms and values that are related to privacy are changing.

The paper by Tassilo Stiller attempts to establish a positive link between the concept of transparency and public trust. In order to do so, he embeds the discussion about governmental transparency into the framework of deliberative democracy. According to this view, government as well as citizenry have to justify their actions to each other, thus engaging in a continuous dialogue with each other.

Though the German Government's management of the recent financial crisis falls short of the ideal of deliberative democracy, Stiller shows that this crisis management could nonetheless be called deliberative. For him the degree of government's responsiveness to the citizens' concerns justifies this classification. Using the German Government's management of the financial crisis as a case study, he concludes that transparency has to go beyond the mere provision of governmental information in order to (re-)establish public trust. Astonishingly and contrary to Stiller's initial assumption, his findings suggest that parliamentary representatives are not able to play a vital role in this process.

The media landscape in the European Union is dominated by national views due to the combination of very few national providers having a European outlook with the scarcity of EU-level alternatives. These national sources, often reporting misleading and wrong statements, provide the foundations for citizens' perceptions on the EU and its institutions. The low levels of citizen trust in the European Commission suggest that it is struggling to overcome this climate of disinformation, perhaps due to its supranational nature which makes it one of the most distant EU institutions. Would better informed citizens trust the European Commission more? Could increased transparency foster trust? For several years, online government ('e-government') has been embraced by the European Commission as a way to increase its legitimacy and to improve its relationship with citizens, as information can be managed in an easier and more cost effective way. However, these technological advances also create challenges for the Commission, as expectations of transparency are increased through knowledge about the possibilities provided by the internet. This chapter, written by Jessie Rooma and Hanna SanNicoló, will investigate the ways in which transparency through e-government could be used to effectively increase citizen trust in the European Commission. Based upon quantitative and qualitative data collected from a sample group of students at Maastricht University and an interview with Mr. Taquet-Graziani from DG Communication, it proposes that accessibility, interaction and publicity should be present, along with pure information dissemination, in order to 
increase trust. In addition, an interested and engaged citizenry is crucial for transparency through e-government to be transformed into trust in the European Commission.

Although most often linked to politics, the concept of transparency extends into other areas of equal importance, such as the health sector. This essay, by Miranda Lindner, uses a case-study to illustrate the proceedings in the pharmaceutical industry and drugreleasing bodies, which remain - unfortunately - unaccountable and highly secretive. More concretely, the study centers around the administration behind the approval of Prozac, the world's most widely prescribed antidepressant, for children and adolescents aged 7 - 18 years in Europe in 2006. In general, it shows that drug companies are most likely to exert the biggest influence - especially in terms of financial incentives - on the American Food and Drug Authority (FDA), which in turn affects the decisions of European drug regulators. Based on the analysis, the essay presents some general recommendations on how to increase transparency with regard to drug approval.

Recently, transparency has become a high profile issue in the development sector. This has been induced by a social movement, known as the Aid Transparency Movement. Since the results of aid efforts are rather disillusioning, this Movement calls for a greater awareness of transparency's potential for improved aid effectiveness. Karolina Gombert Transparency and Development investigates how the concept of 'aid transparency' has been operationalized to achieve aid effectiveness and explores which new conceptualizations can further help to incentivize development. In order to do so, an alternative view on aid transparency is proposed. A distinction between what is called 'donor focused' and 'recipient focused' domains of aid transparency presents the basis for this alternative view. The donor focused domain is concerned with the transparency of suppliers of aid and pays attention to the transparency of financial aid flows. The recipient focused domain foregrounds the beneficiaries of aid and underlines the often presumed causal chain from transparency to what is called 'societal accountability' to development. Societal accountability is defined as citizens' possibility to monitor, scrutinize and hold public office holders accountable. With regard to the recipient focused domain, this article highlights three findings related to transparency: (1) 'Open Data', the idea that access to all data related to the interest of society potentially promotes development, can be understood as exhibiting transparency's mobilization potential, (2) Amartya Sen's approach to development is significant as it reveals that societal accountability must not be conceived as a static concept. Instead, it is to be perceived as being composed of what Sen calls the five human capabilities of "political freedoms, transparency guarantees, economic facilities, protective security and social opportunities", (3) taking the cultural context for transparency to mobilize recipients into account is inalienable, as case studies of Bolivia 
and China demonstrate. These findings imply that aid transparency must be considered in a broader framing of transparency, incorporating different characteristics, such as a catalyst, a capability and a cultural phenomenon. Only if development workers, recipients and donors become aware of these and start to reflect more upon aid transparency, will the current momentum of the Aid Transparency Movement harness the potential to change the perception of development and make aid more effective.

See p. 137 for the bibliography of this section. 